International Journal of

Environmental Research and

Public Health

ISSN 1660-4601

www.mdpi.com/journal/ijerph

Article

\title{
Drunk and Disorganised: Relationships between Bar Characteristics and Customer Intoxication in European Drinking Environments
}

\author{
Karen Hughes ${ }^{1, *}$, Zara Quigg ${ }^{1}$, Mark A. Bellis ${ }^{1}$, Amador Calafat ${ }^{2}$, Ninette van Hasselt ${ }^{3}$, \\ Matej Kosir $^{4}$, Lotte Voorham ${ }^{3}$, Ferry X. Goossens ${ }^{3}$, Mariangels Duch ${ }^{2}$ and Montse Juan ${ }^{2}$ \\ 1 Centre for Public Health, Liverpool John Moores University, Henry Cotton Building, \\ 15-21 Webster Street, Liverpool L3 2ET, UK; E-Mails: z.a.quigg@ljmu.ac.uk (Z.Q.); \\ m.a.bellis@1jmu.ac.uk (M.A.B.) \\ 2 European Institute of Studies on Prevention (IREFREA), Rambla 15, 07003 Palma de Mallorca, \\ Spain; E-Mails: irefrea@irefrea.org (A.C.); mduch@irefrea.org (M.D.); irefrea@cop.es (M.J.) \\ 3 Trimbos-instituut, Da Costakade 45, 3521 VS Utrecht, Netherlands; \\ E-Mails: nhasselt@trimbos.nl (N.V.H.); lvoorham@trimbos.nl (L.V.); \\ fgoossens@trimbos.nl (F.X.G.) \\ 4 Institute for Research and Development "Utrip", Trubarjeva cesta 13, SI-1290 Grosuplje, Ljubljana, \\ Slovenia; E-Mail: info@institut-utrip.si \\ * Author to whom correspondence should be addressed; E-Mail: k.e.hughes@1jmu.ac.uk; \\ Tel.: +44-0-151-231-4510; Fax: +44-0-151-231-4552.
}

Received: 24 September 2012; in revised form: 5 November 2012 / Accepted: 8 November 2012 / Published: 12 November 2012

\begin{abstract}
Preventing alcohol-related harm in drinking environments is a growing international priority. Factors relating to the physical, social and staffing environments in bars can contribute to increased alcohol consumption and harm. Understanding the relationships between such factors and intoxication in European drinking environments is critical to developing appropriate interventions. We undertook a quantitative observational study in 60 bars in four European cities, in The Netherlands, Slovenia, Spain and the UK ( $n=237$ observational visits). Using a structured observational schedule, researchers recorded characteristics of the bar environment and rated customer intoxication levels. All physical bar characteristics showed associations with intoxication before interactions between them were controlled for. Hierarchical modelling found significant independent associations between intoxication and use of plastic glassware, promotion of non-alcoholic
\end{abstract}


drinks (often energy drinks), permissive environments, poor washroom facilities, the presence of a dance floor, customer sexual activity/competitiveness and later observational time. Findings suggest that prevention efforts should focus on raising and enforcing managerial standards in bars. While harm reduction measures such as plastic glassware are often promoted for high risk bars, such measures are inadequate to address public health concerns and insufficient to demonstrate social responsibility.

Keywords: alcohol; intoxication; drinking environments; prevention; harm reduction

\section{Introduction}

Preventing alcohol-related harm in drinking environments is a growing international priority. The World Health Organization's global alcohol strategy [1] identifies drinking environments as key settings for interventions to reduce the negative consequences of alcohol. Suggested policy options include measures to regulate drinking contexts to minimise harm and implement management policies regarding responsible beverage service. Equally, the European alcohol action plan [2] recognises the importance of bar environments in increasing or preventing alcohol-related problems, and suggests the development of guidelines and standards for the design of drinking premises, server training and the monitoring and enforcement of licensing laws. This focus on drinking environments is backed up by a strong body of research showing that high levels of alcohol use and related problems occur in and around bars and nightclubs [3-6]. Binge drinking and intoxication are common among nightlife users [7], and studies consistently associate higher densities of drinking premises with greater alcohol-related harm, particularly violence [8-10]. The presence of intoxicated customers in bars increases risks of such harm [11-13], highlighting the need for prevention measures to focus on reducing intoxication [13].

Alcohol-related harm is often concentrated in specific problematic venues [14]. This can relate to management choices in such venues, including those around bar design, staff practice, entertainment provision and type of clientele targeted $[15,16]$. Recognition of the importance of bar environments in promoting or preventing alcohol-related problems has driven research to identify characteristics of bars that can contribute to alcohol-related harm [15,17-19]; and consequently that can be moderated to prevent harm [11]. A review of these studies identified numerous factors that have emerged as important in predicting greater alcohol use and harm, including poor cleanliness, crowding, loud music, and a permissive environment (i.e., tolerance towards anti-social behaviour) [20]. However, most studies identified had been conducted in non-European settings, and most had focused on alcohol-related harm rather than intoxication. Thus, there is currently a lack of knowledge to inform the development of venue-focused interventions in European drinking environments. To address this gap, we undertook a quantitative observational study in youth-oriented bars in four European cities.

\section{Methods}

The study took place in Utrecht (the Netherlands), Ljubljana (Slovenia), Palma de Mallorca (Spain) and Liverpool (UK) (for further information on each city see [7]). In each city, 15 venues popular with young people were identified for inclusion in the study, providing a sample of 60 venues. Two 
strategies were used to identify venues. In Liverpool, Ljubljana and Utrecht, researchers liaised with relevant authorities to identify all youth-focused bars and categorise these into low, medium or high risk premises based on local data/knowledge of alcohol-related harm. From each group, five premises were randomly selected for the study. In Palma, low, medium and high risk venues were selected based on consultation with local nightlife users.

The observation schedule used to assess premises and the implementation method was based on that developed by Graham et al. [17]. The schedule comprised a range of scale variables and other questions designed to measure aspects of the bar environment (see Appendix Table A1). The original schedule was altered slightly following a research meeting to tailor it to contemporary bar environments in Europe; some items were removed (e.g., pool table atmosphere) and some added (e.g., the price of certain drinks). Research leads from each country undertook a training session to develop consistency in implementing the observational visits, completing the schedule and recognizing and rating intoxication. For the latter, focus was placed on observational indicators that researchers could use to recognise different stages of intoxication, including changes in drinkers' behaviour, appearance and coordination. The training also included a test bar observation, with research leads completing the schedule independently after the visit and comparing and discussing ratings at a meeting the following day. Each research lead then recruited field researchers in their country and repeated the training programme.

In each city, covert one-hour observational visits were undertaken to each venue during peak opening hours on four separate occasions, with days and times of visits varied for each venue. Each observational visit was conducted by a mixed gender pair. Observations took place on Thursday, Friday and Saturday nights (September to December 2010) between 10 p.m. and 5 a.m., with study timings dependent upon local nightlife activity. In Utrecht, researchers were unable to undertake a fourth visit to two premises. Thus, 238 observational visits were undertaken. During observations, researchers were instructed to position themselves in areas with good visibility and to move around to ensure they observed all parts of the venue. They were requested to: behave as customers (being permitted to consume one alcoholic drink); dress in clothing appropriate to the venue; remain as inconspicuous as possible; and avoid unnecessary interaction with other customers. Covert note taking was permitted on mobile phones. Following each visit, researchers independently completed the observational schedule. Paired schedules were later checked at a research meeting with fieldworkers and research leads, with differences between the two schedules discussed and consensus met. Thus, each observation resulted in a single completed schedule. Ethical approval for the study was obtained from Liverpool John Moores University research ethics committee in the UK.

Analysis used SPSS version 17. The primary dependent variable was "intoxication level of people in the venue", measured on a scale of 0 (no sign of intoxication) to 9 (everyone is drunk). This scale had not been completed for one observation in Utrecht and this visit was excluded from analysis ( $n=237$ visits). For environmental characteristics, measures that used a $0-9$ scale were entered as continuous variables with most other data items dichotomised into categorical variables (see Appendix Table A1). Two measures recorded as percentages (customers dancing, seating) were converted into scale variables (see Appendix Table A1). Data completeness was high across all variables ( $>98 \%$ with the exception of individual drink prices; $98 \%$ of visits provided at least one drink price and $67 \%$ 
provided all four drink prices). Missing values were imputed as the city mean for scale variables or the venue norm for dichotomous variables.

Bars can vary their operation at different times and consequently each visit was used as a separate observation in analysis rather than an average being calculated for a venue. City level comparisons of environmental characteristics recorded at each visit used chi squared and ANOVA. For multivariate analysis, scale variables that were highly correlated $(\mathrm{r}>0.50)$ were combined in composite scales (see Appendix Table A1). Analysis used hierarchical modelling (linear mixed modelling) with venue as the unit of observation. All variables were initially input individually to identify associations with intoxication. Variables were then entered into six separate multivariate models relating to: (1) venue entrance; (2) physical environment; (3) bar activities; (4) alcohol and food service; (5) venue staff; and (6) customer factors. Five additional contextual variables were analysed: city; observation time (an equal split between earlier/later observations in each city); number of customers in the premise ( $>100$ or not at the busiest time); whether police were outside the venue during the observation (which may have affected staff/customer behaviour); and whether the venue had an outdoor drinking area. Variables with independent relationships with intoxication ratings within each model were entered into the final models.

\section{Results}

Tables 1 and 2 show the distribution of environmental characteristics recorded during observational visits by city. There were significant differences between cities for most characteristics. For example, door staff were present during fewer observational visits in Ljubljana than in other cities, while alcoholic drink promotions were most commonly seen in Liverpool (Table 1). Observers in Utrecht recorded the highest mean rating on the cleanliness scale (i.e., lower levels of cleanliness). In Palma, most observations identified high alcohol content drinks (predominantly spirits) to be the dominant drink types consumed, whereas in Utrecht low alcohol content drinks (e.g., lager) dominated. Table 1 shows the mean prices of drinks purchased across cities. The mean price of a bottle of lager, for example, ranged from $€ 2.28$ in Utrecht to $€ 4.18$ in Palma. In general, observations in Palma recorded fewer bar staff per customer and more female and older bar staff (Table 2). Across all customer behaviour variables, mean ratings were lowest in Ljubljana although differences between cities were only significant for sexual competition and rowdiness. There were no significant differences between cities in mean ratings of customer intoxication (Liverpool and Utrecht 4.0, Palma 3.7, Ljubljana 3.5, $P=0.313)$.

At the initial stage of hierarchical modelling, significant associations were seen between customer intoxication ratings and all physical environment characteristics, as well as most venue entry characteristics (Table 3). For bar activities, only the presence of a dance floor was associated with higher intoxication ratings, while for alcohol and food service, non-alcoholic (soft) drink promotions and plastic glassware were associated with higher intoxication ratings, and table and food service with lower ratings. For venue staff, the presence of glass collectors, poorer staff monitoring, staff attitude, staff boundaries and higher levels of permissiveness were associated with intoxication. Younger clientele and higher levels of customer dancing, sexual activity/competition (combined scale) and rowdiness were associated with increased intoxication. Of the five contextual variables analysed, only greater number of customers and later observation time were associated with higher intoxication. 
Non-significant variables (city, police outside the venue, outdoor drinking area) were excluded from further analyses.

Table 1. Proportion of observations displaying environmental characteristics, and mean scale ratings for environmental measures, by city of observation.

\begin{tabular}{|c|c|c|c|c|c|c|}
\hline & & Liverpool & Palma & Utrecht & Ljubljana & $P$ \\
\hline Number of venues & & 15 & 15 & 15 & 15 & \\
\hline Number of visits ${ }^{1}$ & & 60 & 60 & 57 & 60 & \\
\hline \multicolumn{7}{|l|}{ Venue entrance } \\
\hline Door staff & $\%$ Yes & 98.3 & 88.3 & 75.4 & 63.3 & $<0.001$ \\
\hline Queue & $\%$ Yes & 15.0 & 35.0 & 31.6 & 13.3 & 0.006 \\
\hline Entrance fee & $\%$ Yes & 11.7 & 40.0 & 14.0 & 26.7 & 0.001 \\
\hline House rules (entry) & $\%$ Yes & 8.3 & 46.7 & 31.6 & 41.7 & $<0.001$ \\
\hline \multicolumn{7}{|l|}{ Physical environment } \\
\hline Seating & Mean & 6.8 & 6.5 & 7.5 & 4.0 & $<0.001$ \\
\hline Noise & Mean & 6.2 & 6.5 & 5.8 & 5.1 & $<0.001$ \\
\hline Crowding & Mean & 4.7 & 3.9 & 5.1 & 3.7 & 0.001 \\
\hline Ventilation & Mean & 2.1 & 3.6 & 3.6 & 2.4 & $<0.001$ \\
\hline Temperature & Mean & 4.2 & 4.7 & 5.4 & 4.4 & $<0.001$ \\
\hline Clearing & Mean & 4.8 & 4.8 & 6.6 & 4.4 & $<0.001$ \\
\hline Glass on floor & Mean & 2.5 & 1.6 & 2.5 & 1.4 & 0.006 \\
\hline Cleanliness & Mean & 4.4 & 4.6 & 6.2 & 4.1 & $<0.001$ \\
\hline Toilets & Mean & 3.8 & 4.1 & 4.0 & 3.8 & 0.764 \\
\hline Lighting & Mean & 3.1 & 4.2 & 3.6 & 2.8 & $<0.001$ \\
\hline \multicolumn{7}{|l|}{ Bar activities } \\
\hline Dance floor & $\%$ Yes & 86.7 & 46.7 & 71.9 & 36.7 & $<0.001$ \\
\hline Pool tables & $\%$ Yes & 6.7 & 11.7 & 0.0 & 6.7 & 0.080 \\
\hline TV screens & $\%$ Yes & 68.3 & 57.1 & 52.6 & 46.7 & 0.103 \\
\hline House rules (inside) & $\%$ Yes & 3.3 & 38.3 & 12.3 & 63.3 & $<0.001$ \\
\hline Rock/heavy music & $\%$ Yes & 3.3 & 31.7 & 5.3 & 23.3 & $<0.001$ \\
\hline Rap/hiphop music & $\%$ Yes & 58.3 & 0.0 & 19.3 & 15.0 & $<0.001$ \\
\hline Pop/dance music & $\%$ Yes & 90.0 & 68.3 & 78.9 & 58.3 & 0.001 \\
\hline \multicolumn{7}{|l|}{ Alcohol and food } \\
\hline Alcoholic drink promotions & $\%$ Yes & 46.7 & 13.3 & 17.5 & 28.3 & $<0.001$ \\
\hline Low drink prices ${ }^{2}$ & $\%$ Yes & 37.9 & 73.3 & 66.7 & 36.7 & $<0.001$ \\
\hline High alcohol drinks & $\%$ Yes & 41.7 & 95.0 & 5.3 & 40.0 & $<0.001$ \\
\hline Soft drink promotions & $\%$ Yes & 1.7 & 21.7 & 21.1 & 15.0 & 0.007 \\
\hline Plastic glassware & $\%$ Yes & 30.0 & 11.9 & 8.8 & 73.3 & $<0.001$ \\
\hline Table service & $\%$ Yes & 3.3 & 25.0 & 7.0 & 78.3 & $<0.001$ \\
\hline Food service & $\%$ Yes & 3.3 & 6.7 & 3.5 & 16.7 & 0.018 \\
\hline
\end{tabular}


Table 1. Cont.

\begin{tabular}{|c|c|c|c|c|c|c|}
\hline & & Liverpool & Palma & Utrecht & Ljubljana & $P$ \\
\hline Price of a bottle of lager (euros) ${ }^{3}$ & Mean & 3.81 & 4.18 & 2.28 & 2.89 & $<0.001$ \\
\hline Price of a glass of wine (euros) & Mean & 3.56 & 3.69 & 2.81 & 2.29 & $<0.001$ \\
\hline $\begin{array}{l}\text { Price of a vodka and orange } \\
\text { (euros) }\end{array}$ & Mean & 3.73 & 7.13 & 5.39 & 4.29 & $<0.001$ \\
\hline Price of a glass of coke (euros) & Mean & 1.69 & 3.65 & 2.10 & 2.02 & $<0.001$ \\
\hline
\end{tabular}

${ }^{1}$ Four visits were made to each venue with the exception of two venues in Utrecht, where only three visits were possible. One visit in Utrecht was excluded as no measurement of intoxication was recorded.

${ }^{2}$ Based on the mean price of either lager or spirits depending on which drink was most commonly being consumed in the venue.

${ }^{3}$ Prices in Liverpool were converted from $£$ sterling to Euros at an exchange rate of 1.1531.

Table 2. Percentage of visits recording staffing and customer factors, and mean ratings for staffing and customer related scales, by city.

\begin{tabular}{|c|c|c|c|c|c|c|}
\hline & & Liverpool & Palma & Utrecht & Ljubljana & $P$ \\
\hline \multicolumn{7}{|l|}{ Staff characteristics } \\
\hline Fewer bar staff & $\%$ Yes & 16.7 & 70.0 & 38.6 & 10.0 & $<0.001$ \\
\hline Young staff & $\%$ Yes & 55.0 & 0.0 & 47.4 & 46.7 & $<0.001$ \\
\hline Male staff & $\%$ Yes & 48.3 & 26.7 & 73.7 & 60.0 & $<0.001$ \\
\hline Glass collectors & $\%$ Yes & 78.3 & 61.7 & 68.4 & 8.3 & $<0.001$ \\
\hline \multicolumn{7}{|l|}{ Staff behaviours } \\
\hline Staff monitoring & Mean & 2.6 & 3.3 & 3.8 & 2.9 & 0.004 \\
\hline Staff coordination & Mean & 4.2 & 5.0 & 4.7 & 3.8 & 0.002 \\
\hline Staff attitude & Mean & 1.5 & 3.2 & 2.1 & 1.7 & $<0.001$ \\
\hline Staff boundaries & Mean & 1.3 & 3.4 & 3.4 & 1.6 & $<0.001$ \\
\hline Permissiveness & Mean & 2.9 & 1.8 & 2.4 & 0.9 & $<0.001$ \\
\hline \multicolumn{7}{|l|}{ Customer type } \\
\hline Male clientele & $\%$ Yes & 60.0 & 75.0 & 63.2 & 81.7 & 0.033 \\
\hline Young clientele & $\%$ Yes & 11.7 & 8.3 & 33.3 & 11.7 & 0.001 \\
\hline Single sex groups & $\%$ Yes & 70.0 & 36.7 & 77.2 & 30.0 & $<0.001$ \\
\hline \multicolumn{7}{|c|}{ Customer behaviours } \\
\hline Dancing & Mean & 4.5 & 3.7 & 4.8 & 3.3 & 0.033 \\
\hline Sexual activity & Mean & 3.2 & 3.1 & 3.0 & 2.6 & 0.436 \\
\hline Sexual competition & Mean & 3.5 & 2.7 & 2.7 & 1.7 & $<0.001$ \\
\hline Rowdiness & Mean & 3.3 & 2.9 & 3.2 & 0.9 & $<0.001$ \\
\hline Movement & Mean & 4.8 & 4.7 & 4.9 & 4.0 & 0.099 \\
\hline \multicolumn{7}{|l|}{ Additional variables } \\
\hline Police outside & $\%$ Yes & 33.3 & 18.3 & 7.3 & 1.7 & $<0.001$ \\
\hline Outdoor area & $\%$ Yes & 23.3 & 66.7 & 63.2 & 86.7 & $<0.001$ \\
\hline $100+$ customers & $\%$ Yes & 63.3 & 81.7 & 59.6 & 35.0 & $<0.001$ \\
\hline Intoxication * & Mean & 4.0 & 3.7 & 4.0 & 3.5 & 0.313 \\
\hline
\end{tabular}

A multivariate analysis was conducted for each block of variables, with models also including customer number and observation time variables. Here, no venue entry characteristics were associated with intoxication ratings (Table 3). Within physical environment variables, greater movement/crowding (combined scale) and poorer washroom facilities were associated with higher ratings. The presence of a 
dance floor and TV screens were the only bar activity factors associated with intoxication. For alcohol and food service, promotion of non-alcoholic drinks and plastic glassware were associated with higher ratings and table service with lower ratings. Poorer staff monitoring and greater permissiveness were the only staff factors associated with higher intoxication. Customer factors associated with higher ratings were younger clientele, dancing, sexual activity/competition and rowdiness.

Table 3. Hierarchical modelling: Associations between environmental characteristics and customer intoxication ratings.

\begin{tabular}{|c|c|c|c|c|c|c|c|c|c|}
\hline & \multirow[b]{3}{*}{ Variable } & & & & & \multicolumn{4}{|c|}{ Multivariate } \\
\hline & & \multicolumn{2}{|c|}{ Bivariate } & \multicolumn{2}{|c|}{ Block analysis } & \multicolumn{2}{|c|}{ Model 1} & \multicolumn{2}{|c|}{ Model 2} \\
\hline & & Estimate & $P$ & Estimate & $P$ & Estimate & $P$ & Estimate & $P$ \\
\hline \multirow{2}{*}{$\begin{array}{l}\text { Contextual } \\
\text { variables \# }\end{array}$} & $>100$ customers & 0.945 & $* * *$ & & & 0.037 & ns & 0.139 & $\mathrm{~ns}$ \\
\hline & Later visit & 1.223 & $* * *$ & & & 0.483 & $*$ & 0.740 & $* * *$ \\
\hline \multirow{4}{*}{$\begin{array}{l}\text { Venue } \\
\text { entrance }\end{array}$} & Door staff & 1.017 & $* *$ & 0.496 & $\overline{\mathrm{ns}}$ & & & & \\
\hline & Queue & 0.715 & $*$ & -0.229 & ns & & & & \\
\hline & Entrance fee & 0.823 & $*$ & 0.124 & ns & & & & \\
\hline & House rules (entry) & 0.201 & $\mathrm{~ns}$ & 0.142 & $\mathrm{~ns}$ & & & & \\
\hline \multirow{8}{*}{$\begin{array}{l}\text { Physical } \\
\text { environment }\end{array}$} & Seating & 0.240 & $* * *$ & 0.062 & $\overline{\mathrm{ns}}$ & & & & \\
\hline & Noise level & 0.282 & $* * *$ & 0.060 & ns & & & & \\
\hline & Movement/Crowding & 0.191 & $* * *$ & 0.087 & $*$ & 0.025 & ns & 0.056 & $\mathrm{~ns}$ \\
\hline & Ventilation/Lighting & 0.280 & $* * *$ & 0.092 & ns & & & & \\
\hline & Temperature & 0.380 & $* * *$ & 0.058 & ns & & & & \\
\hline & Clearing/Cleanliness & 0.139 & $* * *$ & 0.017 & ns & & & & \\
\hline & Glass on floor & 0.296 & $* * *$ & 0.030 & ns & & & & \\
\hline & Toilets & 0.316 & $* * *$ & 0.128 & $*$ & 0.097 & $*$ & 0.103 & * \\
\hline \multirow[t]{7}{*}{ Bar activities } & Dancefloor & 1.252 & $* * *$ & 0.993 & $* * *$ & 0.269 & ns & 0.557 & * \\
\hline & Pool tables & -0.046 & $\overline{\mathrm{ns}}$ & -0.181 & ns & & & & \\
\hline & TV screens & 0.282 & $\mathrm{~ns}$ & 0.569 & $*$ & 0.107 & ns & 0.266 & $\mathrm{~ns}$ \\
\hline & House rules (inside) & -0.132 & $\overline{\mathrm{ns}}$ & -0.093 & ns & & & & \\
\hline & Rock/heavy music & -0.312 & $\overline{\mathrm{ns}}$ & -0.026 & ns & & & & \\
\hline & Rap/hiphop music & 0.080 & $\mathrm{~ns}$ & -0.217 & ns & & & & \\
\hline & Pop/dance music & 0.115 & $\mathrm{~ns}$ & -0.286 & $\mathrm{~ns}$ & & & & \\
\hline \multirow[t]{6}{*}{$\begin{array}{l}\text { Alcohol and } \\
\text { food service }\end{array}$} & $\begin{array}{l}\text { Alcoholic drink } \\
\text { promotions }\end{array}$ & 0.297 & $\mathrm{~ns}$ & 0.336 & ns & & & & \\
\hline & Low drink prices & -0.350 & $\overline{\mathrm{ns}}$ & -0.344 & ns & & & & \\
\hline & Soft drink promotions & 0.888 & $* *$ & 0.833 & $* *$ & 0.631 & $*$ & 0.690 & ** \\
\hline & Plastic glassware & 0.706 & $* *$ & 0.818 & $* *$ & 0.602 & $* *$ & 0.614 & $* *$ \\
\hline & Table service & -0.936 & $* *$ & -0.882 & $* *$ & 0.031 & ns & -0.090 & $\mathrm{~ns}$ \\
\hline & Food service & -1.183 & $*$ & -0.394 & $\mathrm{~ns}$ & & & & \\
\hline \multirow[t]{9}{*}{ Venue staff } & Fewer bar staff & 0.345 & $\mathrm{~ns}$ & -0.027 & $\mathrm{~ns}$ & & & & \\
\hline & Young staff & -0.084 & $\overline{\mathrm{ns}}$ & 0.020 & ns & & & & \\
\hline & Male staff & 0.406 & $\overline{\mathrm{ns}}$ & 0.202 & ns & & & & \\
\hline & Glass collectors & 0.539 & $*$ & 0.235 & ns & & & & \\
\hline & Staff monitoring & 0.209 & $* * *$ & 0.163 & $* *$ & 0.071 & ns & 0.081 & $\mathrm{~ns}$ \\
\hline & Staff coordination & 0.024 & $\mathrm{~ns}$ & -0.113 & ns & & & & \\
\hline & Staff attitude & 0.206 & $*$ & 0.181 & ns & & & & \\
\hline & Staff boundaries & 0.130 & $*$ & 0.052 & ns & & & & \\
\hline & Permissiveness & 0.526 & $* * *$ & 0.425 & $* * *$ & 0.160 & $*$ & 0.298 & $* * *$ \\
\hline
\end{tabular}


Table 3. Cont.

\begin{tabular}{|c|c|c|c|c|c|c|c|c|c|}
\hline & & & & & & \multicolumn{4}{|c|}{ Multivariate } \\
\hline & & \multicolumn{2}{|c|}{ Bivariate } & \multicolumn{2}{|c|}{ Block analysis } & \multicolumn{2}{|c|}{ Model 1} & \multicolumn{2}{|c|}{ Model 2} \\
\hline & Variable & Estimate & $P$ & Estimate & $P$ & Estimate & $P$ & Estimate & $P$ \\
\hline \multirow{7}{*}{$\begin{array}{l}\text { Customer } \\
\text { factors }\end{array}$} & Male clientele & -0.017 & ns & -0.018 & $\mathrm{~ns}$ & & & & \\
\hline & Young clientele & 0.886 & $* *$ & 0.590 & * & 0.316 & $\mathrm{~ns}$ & & \\
\hline & Single sex groups & 0.089 & ns & -0.081 & $\mathrm{~ns}$ & & & & \\
\hline & High alcohol drinks & 0.181 & ns & 0.047 & $\mathrm{~ns}$ & & & & \\
\hline & Dancing & 0.276 & $* * *$ & 0.126 & ** & 0.073 & $\mathrm{~ns}$ & & \\
\hline & $\begin{array}{l}\text { Sexual } \\
\text { activity/competition }\end{array}$ & 0.237 & $* * *$ & 0.085 & * & 0.065 & * & & \\
\hline & Rowdiness & 0.460 & $* * *$ & 0.243 & $* * *$ & 0.125 & $\mathrm{~ns}$ & & \\
\hline
\end{tabular}

Analysis uses hierarchical modelling. \# These two variables were included in all block analyses. ns $=$ not significant; $* P<0.05$; ** $P<0.01 ; * * * P<0.001$. For significant associations in multivariate analyses, slope direction indicates whether the variable was associated with an increase or decrease (-) in intoxication rating.

All variables independently associated with intoxication ratings in block analyses were entered into an overall model (Model 1, Table 3), along with number of customers and observation timing. The model identified six factors independently associated with higher intoxication ratings: later observation time, poorer washroom facilities, non-alcoholic drink promotions, plastic glassware, greater permissiveness and higher customer sexual activity/competition. As customers will be attracted to venues based on their social and physical environments, a second model was constructed that excluded customer-focused variables. Here, all independent associations between non-customer factors and intoxication remained, and those with later observation timing, non-alcoholic drink promotions and permissiveness were strengthened. An independent relationship also emerged between intoxication ratings and the presence of a dance floor.

\section{Discussion}

This study is among the first to explore associations between intoxication and environmental factors in European bars, and the first to do so cross-nationally. The study's multi-country nature means findings may have been affected by structural and cultural factors, such as differences in licensing legislation and variation in the interpretation of bar characteristics and intoxication across research teams. To address this latter point, we used an established methodology [17,19] and a detailed training programme to develop consistency in measurement recording. Nevertheless, the relatively small variations seen between cities in ratings of intoxication may in part be due to variations in researchers' cultural exposure and norms for what was considered drunk. Drink prices cannot be considered representative for each city, while drink serving sizes and strengths may have varied [21]. Further, as with all cross-sectional studies, we cannot ascertain causal relationships between bar characteristics and intoxication. However, our study does identify characteristics of bars where intoxication may be more likely, and consequently provides intelligence to inform bar-focused interventions to prevent alcohol-related harm.

Several of our findings are consistent with research elsewhere. Many characteristics typically associated with alcohol-related harm (e.g., loud music, crowding, lack of seating) [20] were associated 
with intoxication in bivariate analysis, and some that were significant in multivariate analysis have been identified as risk factors elsewhere. For example, permissive bar environments, poor cleanliness (e.g., poorer washroom facilities) and measures of sexual competition have been associated with aggression and disorder in studies in Canada [17], Australia [22] and Scotland [12].

Other aspects of our findings are novel. Thus, this is the first observational study to identify associations between intoxication and both plastic glassware and promotion of non-alcohol drinks. Plastic glassware is widely used as a harm reduction measure in drinking premises, with the aim of preventing serious injuries following the use of glassware as a weapon [23,24]. In some countries its use can be mandated through licensing legislation. In Glasgow, Scotland, glass was banned in late night drinking venues in 2006. There were some exceptions, and a study found that disorder in bars that used only plastic glassware resulted in fewer injuries than that occurring in bars where glass was still used [24]. Plastic glassware can therefore help reduce injury in bars, yet does little to prevent violence nor, as our study indicates, the intoxication that drives this. Thus, use of plastic glassware should not be considered sufficient to demonstrate responsible management; its use must be accompanied by action to reduce intoxication in order to prevent broader alcohol-related harms, including those that can occur when intoxicated individuals leave the relative safety of glass-free premises [25].

A more surprising finding was the association between non-alcoholic drink promotions and higher intoxication ratings. There are several possibilities for this. Firstly, as with plastic glassware, the promotion of non-alcoholic drinks may reflect a concerted effort in problematic premises to reduce harm. Another explanation may relate to modern drinking patterns. A survey conducted alongside this study found high levels of preloading among nightlife users in the four cities [7]. With many customers entering bars after having already consumed significant quantities of alcohol, venue managers may consider non-alcoholic drinks to provide greater potential for sales; particularly legal sales since service of alcohol to intoxicated individuals is often illegal. Preloading may also account for the lack of association between intoxication and cheap alcoholic drink promotions, lower alcohol prices or high alcohol content drinks. However, the most plausible explanation might be provided by the fact that many non-alcoholic drinks promoted were "energy" drinks (e.g., containing caffeine). These drinks are commonly used as mixers with spirits, can desensitise users to the symptoms of intoxication, can have diuretic effects that can increase thirst, and are used as stimulants by nightlife users to help them stay awake and continue drinking over long nights [26,27]. Bars may exploit these effects and promote energy drinks to encourage customers to continue purchasing and consuming drinks. Numerous studies have identified increased risks of intoxication and alcohol-related problems among individuals that consume alcohol mixed with energy drinks [28-30]. Any efforts to promote non-alcoholic drinks in bars as a preventive measure should be implemented with caution, and should specifically exclude energy drinks.

In line with customer behaviour reflecting bar policy, after customer-focused variables were removed from analyses the relationship between permissive environments and intoxication was strengthened. Bars that tolerate intoxication and raucous behaviour are likely to attract individuals who want to get drunk and behave in ways that may prevented elsewhere. Among other managementfocused variables only poor washroom facilities, a potential marker of staff negligence, was associated with intoxication in our final models. However, all physical environment characteristics showed strong 
associations with intoxication before interactions between them were controlled for. This indicates that factors such as inadequate glass clearing, poor cleanliness, and poor ventilation and lighting cluster in high risk bars, suggesting a general lack of managerial care in such premises. Thus, while poor physical environments may not cause intoxication per se, they could be considered as a syndrome diagnostic of venues where intoxication and harm is likely. The development of standards for licensed premises is recommended through international alcohol strategies [1,2]. However, evidence for the effectiveness of such measures as standalone interventions is scant [31]. Where management-focused interventions have shown success they have typically been backed up by strong enforcement and packaged within multi-agency programmes [15,31-33]. The importance of enforcing and monitoring licensing legislation is also recognised in international strategies. Ensuring such activity is implemented alongside measures to train staff and develop standards should be considered imperative.

Professionally-managed bars have the potential to reduce drunkenness and so contribute to both safer drinking environments and public health. Venue staff can control access to alcohol, manage confrontation, provide environments where abusive behaviour is not tolerated, and offer customer care services. Whilst we have identified the potential impacts of poor bar management, other drinking environments (e.g., private parties, public spaces) offer little opportunity for managing drinkers' behaviour and safety. Recent years have seen a trend in Europe towards reduced alcohol sales in ontrade premises and increased sales in supermarkets and shops for consumption in private settings, driven largely by cheaper off-sales prices [34]. In the longer term, providing well-managed environments where people can socialise safely may be a more sustainable strategy for professional bar operators than focusing purely on selling large quantities of alcohol. Whilst strategies should aim to create well-managed bars that do not permit drunkenness, such practices are likely to be helped by regulation that prevents the sale of cheap alcohol elsewhere.

\section{Conclusions}

Preventing harm in drinking environments requires interventions that recognise and address the contributors to intoxication. Consistent with international research, our study suggests that venues where intoxication occurs can have a clustering of "bad" environmental features that manifest through poor managerial care. The variables with the strongest relationships with intoxication ratings were permissiveness (identified as a general indifference towards patrons' behaviours) and later observation time. Thus, permissive late night venues are likely to attract individuals who want to get (or are already) drunk and provide environments with few behavioural expectations. In such venues, harm reduction measures such as plastic glassware can be common, implemented specifically to prevent intoxicated aggression turning into serious injury. These measures may be tokenistic; having little impacts on sales and profits and being relatively easy for venues to adopt, whether to demonstrate social responsibility or meet licensing requirements. However, they do little to address the root causes of harm. Our findings suggest that greater focus on managerial practice is needed. All features of the physical, social and staffing environment within bars stem from management decisions, including how venues are designed, how staff are trained, and how customers are permitted to behave. In some circumstances, attracting heavy drinking patrons may represent a commercially attractive model despite the poor health and anti-social outcomes associated with drunkenness. While many 
establishments may be well placed to adopt recognised managerial standards some of the most risky will only change when faced with regulation and enforcement.

\section{Acknowledgements}

The research leading to these results has received funding from the European Community's Seventh Framework Programme (FP7/2007-13) under grant agreement No.223 059-Alcohol Measures for Public Health Research Alliance (AMPHORA). We would like to thank Kathryn Graham for her permission to use the research tools used in the study and her advice in its implementation. We would also like to thank Alasdair Forsyth for his advice in developing the study. We are grateful to all the researchers who assisted with the study implementation, particularly Sara Wood, Adam Caris, Lindsay Eckley, Steve Duggan, Ian Wood, Sanela Talić, Mirela Brkić, Joanne van der Leun, Cristina Gelabert, Marc Riera, Noelia Martínez, Rafael Umbert and Joan Recasens. We also thank Peter Anderson and Antoni Gual for their comments on the manuscript.

\section{Conflicts of Interest}

In the past three years, the Centre for Public Health has received a grant from Drinkaware to undertake an independent study of drinking behaviours among students and MAB has provided them with independent medical advice. Drinkaware is an independent UK-wide charity supported by voluntary contributions from the alcohol and supermarket industries and governed through a memorandum of understanding between the Department of Health, Home Office, Scottish Executive, Welsh Assembly Government, Northern Ireland Office and Portman Group.

\section{References}

1. World Health Organization. Global Strategy to Reduce the Harmful Use of Alcohol. World Health Organization: Geneva, 2010. Available online: http://www.who.int/substance_abuse/activities/ gsrhua/en/ (accessed on 9 November 2012).

2. World Health Organization Regional Office for Europe. European Action Plan to Reduce the Harmful Use of Alcohol 2012-2020. World Health Organization Regional Office for Europe: Copenhagen, 2011. Available online: http://www.euro.who.int/en/who-we-are/governance/ regional-committee-for-europe/past-sessions/sixty-first-session/documentation/workingdocuments/wd13-european-action-plan-to-reduce-the-harmful-use-of-alcohol-20122020 (accessed on 9 November 2012).

3. Gmel, G.; Heeb, J.L.; Rezny, L.; Rehm, J.; Kuo-Mohler, M. Drinking patterns and traffic casualties in Switzerland: Matching survey data and police records to design preventive action. Public Health 2005, 5, 426-436.

4. Rowe, S.C.; Wiggers, J.H.; Wolfenden, L.; Francis, J.L. Establishments licensed to serve alcohol and their contribution to police-recorded crime in Australia: Further opportunities for harm reduction. J. Stud. Alcohol Drugs 2010, 71, 909-916. 
5. Bellis, M.A.; Hughes, K.; Quigg, Z.; Morleo, M.; Jarman, I.; Lisboa, P. Cross-sectional measures and modelled estimates of blood alcohol levels in UK nightlife and their relationships with drinking behaviours and observed signs of inebriation. Subst. Abuse Treat. Prev. Policy 2010, 5 , doi:10.1186/1747-597X-5-5.

6. Clapp, J.D.; Reed, M.B.; Win, J.W.; Shillington, A.M.; Croff, J.; Holmes, M.R.; Trim, R.S. Blood alcohol concentrations among bar patrons: A multi-level study of drinking behaviour. Drug Alcohol Depend. 2009, 102, 41-48.

7. Hughes, K.; Quigg, Z.; Bellis, M.A.; van Hasselt, N.; Calafat, A.; Kosir, M.; Juan, M.; Duch, M.; Voorham, L. Drinking behaviours and blood alcohol concentration in four European drinking environments: A cross-sectional study. BMC Public Health 2011, 11, doi:10.1186/1471-2458-11-918.

8. Livingston, M.; Chikritzhs, T.; Room, R. Changing the density of alcohol outlets to reduce alcohol-related problems. Drug Alcohol Rev. 2007, 26, 557-566.

9. Grubesic, T.H.; Pridemore, W.A. Alcohol outlets and clusters of violence. Int. J. Health Geogr. 2011, 10, doi:10.1186/1476-072X-10-30.

10. Livingston, M. Alcohol outlet density and harm: Comparing the impacts on violence and chronic harms. Drug Alcohol Rev. 2011, 30, 515-523.

11. Homel, R.; Carvolth, R.; Hauritz, M.; McIlwain, G.; Teague, R. Making licensed premises safer for patrons: What environmental factors should be the focus of interventions? Drug Alcohol Rev. 2004, 23, 19-29.

12. Forsyth, A.J.M. Assessing the Relationships between Late Night Drinks Marketing and AlcoholRelated Disorder in Public Space. Available online: http://alcoholresearchuk.org/2007/04/06/ relationships-between-late-night-drinks-marketing-and-alcohol-related-disorder/ (accessed on 9 November 2012).

13. Graham, K.; Osgood, D.W.; Wells, S.; Stockwell, T. To what extent is intoxication associated with aggression in bars? A multilevel analysis. J. Stud. Alcohol 2006, 67, 382-390.

14. Newton, A.D.; Hirschfield, A. Measuring violence in and around licensed premises: The need for a better evidence base. Crime Prevent. Commun. Saf. 2009, 11, 153-170.

15. Graham, K.; Homel, R. Raising the Bar: Preventing Aggression in and Around Bars, Pubs and Clubs. Willan Publishing: Cullompton, Devon, UK, 2008; pp. 58-168.

16. Madensen, T.D.; Eck, J.E. Violence in bars: Exploring the impact of place manager decision-making. Crime Prevent. Commun. Saf. 2008, 10, 111-125.

17. Graham, K.; Bernard, S.; Osgood, D.W.; Wells, S. Bad nights or bad bars? Multi-level analysis of environmental predictors of aggression in late-night large-capacity bars and clubs. Addiction 2006, $101,1569-1580$.

18. Green, J.; Plant, M.A. Bad bars: A review of risk factors. J. Subst. Abuse 2007, 12, 157-189.

19. Graham, K.; La Rocque, L.; Yetman, R.; Ross, T.J.; Guistra E. Aggression and barroom environments. J. Stud. Alcohol 1980, 41, 277-292.

20. Hughes, K.; Quigg, Z.; Eckley, L.; Bellis, M.A.; Jones, L.; Calafat, A.; Kosir, M.; van Hasselt, N. Environmental factors in drinking venues and alcohol-related harm: The evidence base for European intervention. Addiction 2011, 106, 37-46.

21. Gual, A.; Martos, A.R.; Lligona, A.; Llopis, J.J. Does the concept of a standard drink apply to viticultural societies? Alcohol Alcohol. 1999, 34, 153-160. 
22. Homel, R.; Clark, J. The Prediction and Prevention of Violence in Pubs and Clubs. Crime Prevention Studies; Criminal Justice Press: New York, NY, USA, 1994.

23. Anderson, Z.; Whelan, G.; Hughes, K.; Bellis, M.A. Evaluation of the Lancashire Polycarbonate Glass Pilot Project. Available online: http://www.cph.org.uk/showPublication.aspx?pubid=561 (accessed on 9 November 2012).

24. Forsyth, A.J.M. Banning glassware from nightclubs in Glasgow (Scotland): Observed impacts, compliance and patron's views. Alcohol Alcohol. 2008, 43, 111-117.

25. Bellis, M.A.; Hughes, K. Getting drunk safely? Night-life policy in the UK and its public health consequences. Drug Alcohol Rev. 2011, 30, 536-545.

26. Ferreira, S.E.; De Mello, M.T.; Pompeia, S.; De Souza-Formigoni, M.L.O. Effects of energy drink ingestion on alcohol intoxication. Alcohol Clin. Exp. Res. 2006, 30, 598-605.

27. Marczinski, C.A. Alcohol mixed with energy drinks: Consumption patterns and motivations for use in U.S. college students. Int. J. Environ. Res. Public Health 2011, 8, 3232-3245.

28. Thombs, D.L.; O’Mara, R.J.; Tsukamoto, M.; Rossheim, M.E.; Weiler, R.M.; Merves ML; Goldberger, B.A. Event-level analyses of energy drink consumption and alcohol intoxication in bar patrons. Addict. Behav. 2010, 35, 325-330.

29. O’Brien, M.C.; McCoy, T.P.; Rhodes, S.D.; Wagoner, A.; Wolfson, M. Caffeinated cocktails: Energy drink consumption, high-risk drinking, and alcohol-related consequences among college students. Acad. Emerg. Med. 2008, 15, 453-460.

30. Brache, K.; Stockwell, T. Drinking patterns and risk behaviors associated with combined alcohol and energy drink consumption in college drinkers. Addict. Behav. 2011, 36, 1133-1140.

31. Jones, L.; Hughes, K.; Atkinson, A.M.; Bellis, M.A. Reducing harm in drinking environments: A systematic review of effective approaches. Health Place 2011, 17, 508-518.

32. Wallin, E.; Norstrom, T.; Andreasson, S. Alcohol prevention targeting licensed premises: A study of effects on violence. J. Stud. Alcohol 2003, 64, 270-277.

33. Warpenius, K.; Holmila, M.; Mustonen, H. Effects of a community intervention to reduce the serving of alcohol to intoxicated patrons. Addiction 2010, 105, 1032-1040.

34. Hughes, K.; Bellis, M.A. Drinking Environments. In Alcohol in the European Union: Consumption, Harm and Policy Approaches; Anderson P, Moller L, Galea G, Eds.; World Health Organization Regional Office for Europe: Copenhagen, Denmark, 2012; pp. 63-68. 
Table A1. Description of observational schedule measurements used in analyses.

\begin{tabular}{|c|c|c|c|c|}
\hline \multicolumn{2}{|l|}{ Scale variables } & \multicolumn{3}{|c|}{ Categorical variables } \\
\hline Label & Scale & Scale range & Label & Yes/No \\
\hline Intoxication * & $\begin{array}{l}\text { Intoxication level of people in the } \\
\text { venue }\end{array}$ & 0 no sign of intoxication $9 \rightarrow$ everyone is drunk & Door staff & Staff managing entrance to the venue \\
\hline \multirow[t]{2}{*}{ Seating } & \multirow{2}{*}{$\begin{array}{l}\text { Proportion of the venue floor space } \\
\text { containing seating }\end{array}$} & \multirow[t]{2}{*}{$090 \%$ or more $\rightarrow 9<10 \%$} & \multirow{2}{*}{$\begin{array}{l}\text { Queue } \\
\text { Entrance fee }\end{array}$} & There was a queue to enter the venue \\
\hline & & & & Entrance fee had to be paid \\
\hline Noise & Noise level in loudest part of venue & $\begin{array}{l}0 \text { very quiet/easy to talk } \rightarrow 9 \text { hurts ears/cannot } \\
\text { talk }\end{array}$ & House rules (entry) & House rules displayed at venue entrance \\
\hline Crowding $^{\text {a }}$ & $\begin{array}{l}\text { Crowding at busiest time } \\
\text { (exc.dancefloor) }\end{array}$ & 0 lots of space $\rightarrow 9$ cannot move & Dance floor & Venue had a designated dance floor area \\
\hline Movement $^{\mathrm{a}}$ & $\begin{array}{l}\text { Movement (at busiest time/part of } \\
\text { venue) }\end{array}$ & 0 little movement $\rightarrow 9$ constant & Pool tables & Venue had pool tables \\
\hline Ventilation $^{b}$ & Ventilation in the venue & 0 extremely fresh $\rightarrow 9$ extremely stuffy/stale & TV screens & Television screens ${ }^{\mathrm{g}}$ visible in the venue \\
\hline Lighting ${ }^{b}$ & Level of lighting inside the venue & $\begin{array}{l}0 \text { bright/can clearly see } \rightarrow 9 \text { very dark/can } \\
\text { hardly see }\end{array}$ & House rules (venue) & House rules displayed inside the venue \\
\hline Temperature & Temperature in the venue & 0 very cold $\rightarrow 9$ very warm & Rock/heavy music & Rock/heavy metal music being played \\
\hline Clearing $^{\mathrm{c}}$ & Clearing of tables/other surfaces ${ }^{\mathrm{e}}$ & 0 always $\rightarrow 9$ never & Rap/hip hop music & Rap or hip hop music being played \\
\hline \multirow[t]{2}{*}{ Cleanliness $^{c}$} & \multirow{2}{*}{$\begin{array}{l}\text { Extent that indoor premises are kept } \\
\text { clean (spills, litter) including the } \\
\text { floor }\end{array}$} & \multirow[t]{2}{*}{0 always $\rightarrow 9$ never } & Pop/dance music & Pop or dance music being played \\
\hline & & & $\begin{array}{l}\text { Alcoholic drink } \\
\text { promotions }\end{array}$ & Cheap drink promotions ${ }^{\mathrm{h}}$ offered \\
\hline Glass on floor & $\begin{array}{l}\text { Extent of glass/bottles on venue } \\
\text { floor }^{\mathrm{f}}\end{array}$ & 0 none $\rightarrow 9$ everywhere & Low drinks prices & Drink prices below average for that city ${ }^{i}$ \\
\hline \multirow[t]{2}{*}{ Toilets } & \multirow{2}{*}{$\begin{array}{l}\text { Extent that toilets are kept in order } \\
\text { (e.g., locks) and stocked (soap, toilet } \\
\text { rolls etc.) }\end{array}$} & \multirow[t]{2}{*}{0 clean/fresh/stocked $\rightarrow 9$ vandalised/foul } & Soft drink promotions & Non-alcoholic drinks promoted $^{\mathrm{j}}$ \\
\hline & & & Plastic glassware & Drinks served in plastic glasses $\mathrm{k}$ \\
\hline \multirow{2}{*}{$\begin{array}{l}\text { Staff } \\
\text { monitoring } \\
\end{array}$} & \multirow{2}{*}{$\begin{array}{l}\text { To what extent are staff generally } \\
\text { monitoring all areas of the venue? }\end{array}$} & \multirow[t]{2}{*}{0 constantly monitored $\rightarrow 9$ unmonitored } & Table service & Drinks served at tables \\
\hline & & & Food service & Food available during the observation \\
\hline \multirow{2}{*}{$\begin{array}{l}\text { Staff } \\
\text { coordination }\end{array}$} & \multirow{2}{*}{$\begin{array}{l}\text { To what extent do staff seem to be } \\
\text { coordinated as a team? }\end{array}$} & \multirow{2}{*}{$\begin{array}{l}0 \text { constant radio or eye contact } \rightarrow 9 \text { not } \\
\text { coordinated at all }\end{array}$} & Fewer bar staff & 30 or more customers per bar server \\
\hline & & & Young staff & $>50 \%$ thought to be under age 25 \\
\hline \multirow[t]{3}{*}{ Staff attitude } & \multirow{3}{*}{$\begin{array}{l}\text { Are servers cheerful, courteous and } \\
\text { friendly (CCF) in a professional way } \\
\text { or distant, unfriendly, stern or even } \\
\text { rude/obnoxious (DUS)? }\end{array}$} & \multirow[t]{3}{*}{0 all were $\mathrm{CCF} \rightarrow 9$ all were DUS } & Male staff & $>50 \%$ male \\
\hline & & & Glass collectors & Glass collectors working in the venue \\
\hline & & & Male clientele & $>50 \%$ clientele were male \\
\hline \multirow{2}{*}{$\begin{array}{l}\text { Staff } \\
\text { boundaries }\end{array}$} & \multirow{2}{*}{$\begin{array}{l}\text { Extent that servers maintained } \\
\text { professional }(\mathrm{P}) \text { boundaries from } \\
\text { patrons }\end{array}$} & \multirow{2}{*}{$\begin{array}{l}0 \text { all completely } \mathrm{P} \text {, clear boundaries } \rightarrow \text { all } \\
\text { socialising with customers }\end{array}$} & Young clientele & $>50 \%$ clientele estimated to be $<$ age 22 \\
\hline & & & Single sex groups & $>50 \%$ clientele in single sex groups \\
\hline
\end{tabular}


Table A1. Cont.

\begin{tabular}{|c|c|c|c|c|}
\hline \multicolumn{2}{|l|}{ Scale variables } & \multicolumn{3}{|c|}{ Categorical variables } \\
\hline Label & Scale & Scale range & Scale & Label \\
\hline \multirow[t]{2}{*}{ Permissiveness } & \multirow[t]{2}{*}{$\begin{array}{l}\text { Overall decorum /behavioural } \\
\text { expectations }\end{array}$} & \multirow[t]{2}{*}{$\begin{array}{l}0 \text { no offensive/abusive behaviour } \rightarrow 9 \text { anything } \\
\text { goes }\end{array}$} & High alcohol drinks & $\begin{array}{l}\text { High alcohol content }{ }^{1} \text { drinks most } \\
\text { common }\end{array}$ \\
\hline & & & Police outside & Police were outside the venue at entry \\
\hline Dancing & Proportion of customers dancing & $0<10 \% \rightarrow 990 \%$ or more & Outdoor area & Outdoor eating/drinking/smoking area \\
\hline $\begin{array}{l}\text { Sexual } \\
\text { activity }\end{array}$ & Sexual activity in venue & 0 none $\rightarrow 9$ explicit sexual contact & $100+$ customers & $100+$ customers in venue at peak time \\
\hline $\begin{array}{l}\text { Sexual } \\
\text { competition }\end{array}$ & Sexual competition in venue & $\begin{array}{l}0 \text { scoping not the focus for anyone } \rightarrow 9 \text { scoping } \\
\text { the focus of } 76-100 \%\end{array}$ & Later visit & Later $50 \%$ of observations (per city) \\
\hline Rowdiness & $\begin{array}{l}\text { Global rating of rowdiness in the } \\
\text { venue }\end{array}$ & 0 none/very rare $\rightarrow 9$ out of control & & \\
\hline
\end{tabular}

* Main variable of interest. The following variables were strongly correlated and were combined into single scales measured from 0 to $18:{ }^{\text {a }}$ Crowding and movement ( $\mathrm{r}=0.686$; cronbach's alpha 0.813); ${ }^{\mathrm{b}}$ Ventilation and Lighting $\left(\mathrm{r}=0.607\right.$; cronbach's alpha 0.755); ${ }^{\mathrm{c}}$ Clearing and Cleanliness $(\mathrm{r}=0.788$; cronbach's alpha 0.881);

${ }^{\mathrm{d}}$ Sexual activity and Sexual competition ( $\mathrm{r}=0.765$; cronbach's alpha 0.866$)$; ${ }^{\mathrm{e}}$ Highest rating from two scales covering tables/other surfaces separately; ${ }^{\mathrm{f}}$ Highest rating from two scales covering glass/bottles separately; ${ }^{\mathrm{g}}$ Typically showing music videos or venue marketing/promotions; ${ }^{\mathrm{h}}$ e.g., buy one get one free, free shots; ${ }^{\mathrm{i}}$ Based on spirits or lager depending on which drink was most commonly being consumed in the venue; ${ }^{j}$ Including energy drinks; ${ }^{k}$ Partly or wholly; ${ }^{1}$ High alcohol: spirits/wine, low alcohol: lager/cider/alcopops.

(C) 2012 by the authors; licensee MDPI, Basel, Switzerland. This article is an open access article distributed under the terms and conditions of the Creative Commons Attribution license (http://creativecommons.org/licenses/by/3.0/). 